PAPER

You may also like

\title{
EMHD flow of non-Newtonian nanofluids over thin needle with Robinson's condition and Arrhenius pre-exponential factor law
}

To cite this article: Fazle Mabood et al 2020 Phys. Scr. 95115219

View the article online for updates and enhancements. 


\title{
EMHD flow of non-Newtonian nanofluids over thin needle with Robinson's condition and Arrhenius pre-exponential factor law
}

\author{
Fazle Mabood ${ }^{1}\left(\mathbb{D}\right.$, Taseer Muhammad $^{2}$, M K Nayak $^{3}$, Hassan Waqas ${ }^{4}$ and \\ O D Makinde ${ }^{5}$

\footnotetext{
${ }^{1}$ Department of Information Technology, Fanshawe College London ON, Canada

${ }^{2}$ Department of Mathematics, College of Sciences, King Khalid University, Abha 61413, Saudi Arabia

${ }^{3}$ Department of Physics, IHSE, Siksha 'O' Anusandhan Deemed to be University, Bhubaneswar-751003, India

${ }^{4}$ Department of Mathematics, Government College University Faisalabad, Layyah Campus 31200, Pakistan

${ }^{5}$ Faculty of Military Science, Stellenbosch University, Private Bag X2, Saldanha 7395, South Africa
}

E-mail: tasgher@kku.edu.sa and taseer_qau@yahoo.com

Received 11 August 2020, revised 1 October 2020

Accepted for publication 13 October 2020

Published 21 October 2020

\begin{abstract}
Many researchers and scientists are devoting their time to scrutinize nanofluids nature and characteristics for heat transfer enhancement. The scrutiny of nanoliquids is important in the large scale thermal management systems via evaporators, advanced cooling systems, heat exchangers, micro/nano-electromechanical devices and industrial chilling applications.

Nanoliquids are very momentous even in the natural process via different fields like chemistry, chemical engineering, physics and biology. Nanoliquids can be utilized in various fields of engineering such as different chemical procedures, cooling of electronic equipment and heat exchangers. The main aim of current article is to scrutinize electromagnetohydrodynamic flow of micropolar-Casson-Carreau nanoliquids over thin needle with Robinson's conditions and Arrhenius pre-exponential factor law. Double stratification effects are also taken into account. The reverent partial differential equations are reformulated into the system of ordinary differential expressions by implementing appropriate transformations. Such obtained equations subject to boundary constraints are computed numerically by considering Runge-Kutta-Fehlberg method. Behaviour of numerous interesting parameters on flow fields is deliberated. The outcomes of flow fields are delineated through graphs and tabular data.
\end{abstract}

Keywords: electromagnetohydrodynamic flow, double stratification, non-Newtonian nanofluids, Robinson's conditions, Arrhenius pre-exponential factor law, Thin needle

(Some figures may appear in colour only in the online journal)

\section{Introduction}

Nanofluids include nanomaterials of less than $100 \mathrm{~nm}$ of suspension diameter that are utilized for improvement of thermal conductivity. Applications of the nanofluids are used for electric heating water, increased storage, refrigerator, condenser heat transfer performance and efficient solar power absorption. The novel characteristics of nanoliquids include impressive heat transport and thermal conductivity enhancements. Recent survey depicts a significant increase in the applications of nanoliquids in the several kinds of micro-systems such as microchannels, micro heat pipes and micro-reactors. There is further significant potential in utilizing the nanoliquids in the medical sciences like bio-separation systems, enzyme biosensors, biomimetic microsystems and drug delivery systems. Nanofluids are used in the cooling of industrial machines, nuclear plants, transformer oils and nanoelectronic.

Choi and Eastman [1] initiated nanofluid flow. Buongiorno [2] established the model of nanofluid flow together with 


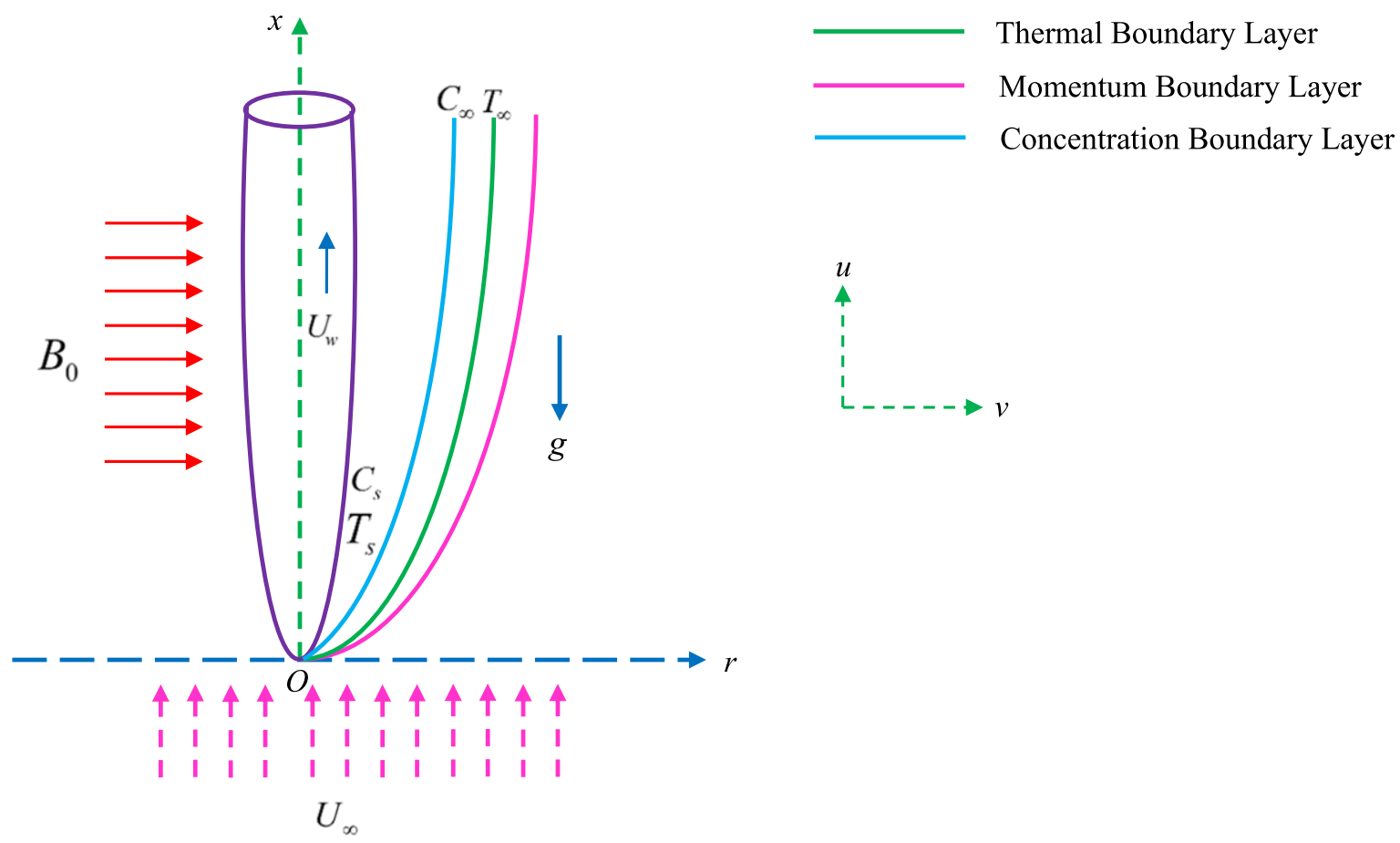

Figure 1. Flow representation of the problem.
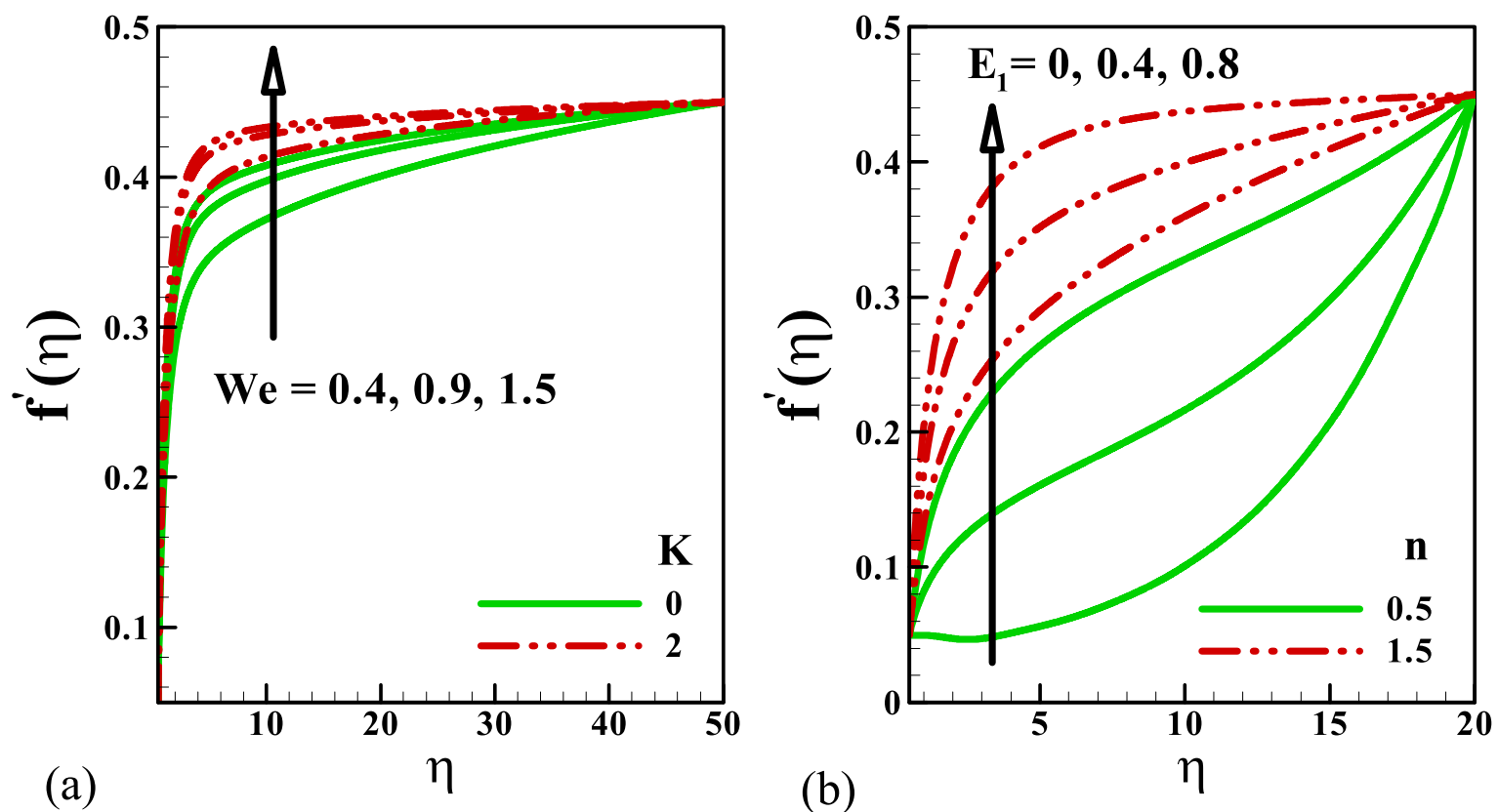

Figure 2. Outcomes of $f^{\prime}$ versus (a) $W e, K$ (b) $E_{1}, n$.

Brownian motion and thermophoretic aspects. Ali et al [3] studied the development structure of cylinder for cross-liquid movement of nanoparticles in an electromagnetic environment. Shah et al [4] scrutinized Maxwell nanofluid movement between vertical sheets with heat flux and convection effects. Ahmed et al [5] examined the mixed convection effect in Maxwell nanoliquids 3D flow by vertical stretching cylinder. Hayat et al [6] addressed the stagnation point movement of
non-Newtonian liquid (Carreau liquid) by numerical simulation with Cattaneo-Christov thermal gradient. Tlili et al [7] discussed the 3D magnetohydrodynamic (MHD) Maxwell nanofluid flow with heat diffusion/generative impacts. Khan et al [8] explored boundary-layer movement of Maxwell nanoliquids through an extendable revolving cylinder subject to transverse magnetosphere. Riaz et al [9] investigated the MHD Maxwell liquid flow processing concerning local and non-local 


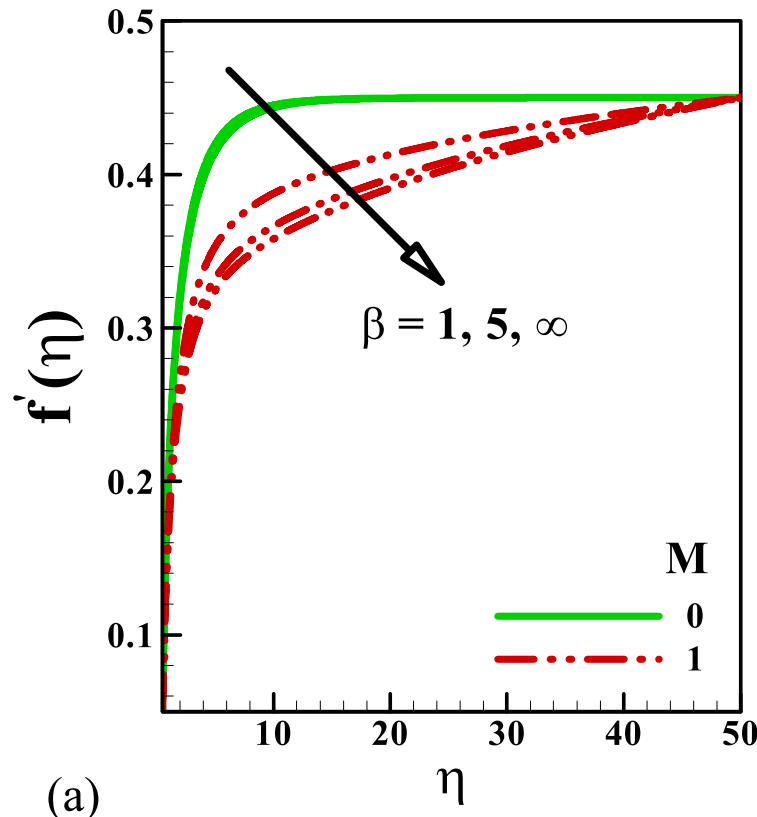

(a)

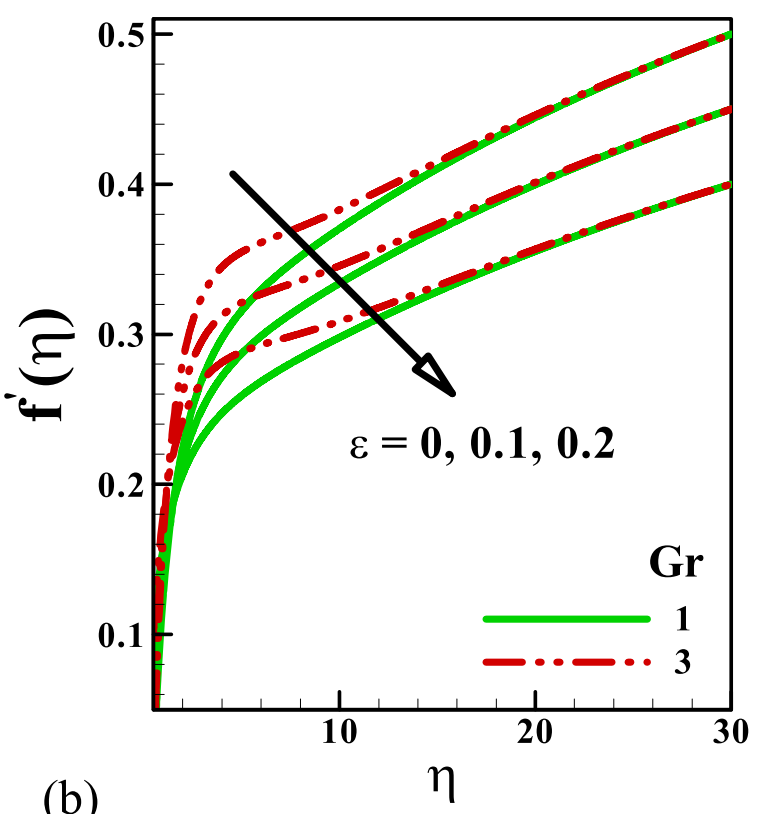

(b)

Figure 3. Outcomes of $f^{\prime}$ versus (a) $\beta, M$ (b) $G r, \varepsilon$.
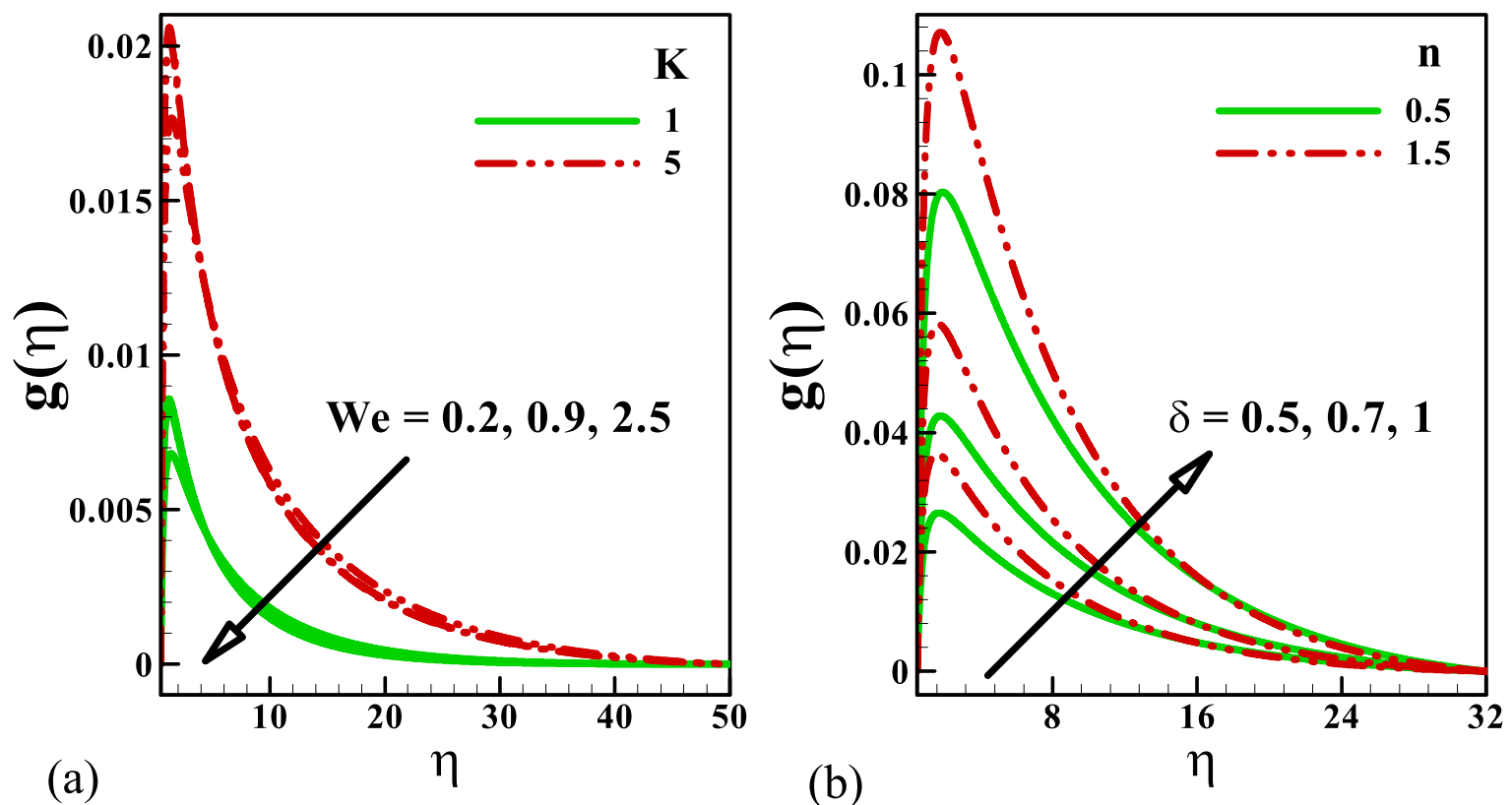

Figure 4. Outcomes of $g(\eta)$ versus (a) We, $K$ (b) $\delta, n$.

differentiated operators. Vahid et al [10] scrutinized boundarylayer nanoliquid flow and heat and mass transport over the surface. Hayat et al [11] addressed Carreau liquid peristaltic MHD flow in a medium of different waveforms. Ellahi et al [12] discussed the function of slipping in a two-phase movement of the Newtonian liquids. Shafee et al [13] investigated the simulation model for turbulent flow in a pipe via a hybrid swirling movement system that assumes nanofluid energy deficiency. Iftikhar et al [14] investigated the effect of ferromagnetic dipole on the flow of a nanofluid through a stretching cylinder. Raza [15] examined the cumulative impact of thermal radiation and velocity slip along with the convective heated stretching sheet. Many researcher works on the nanofluids which are carried out via studies [16-33].

\section{Mathematical formulation}

Steady, incompressible electromagnetic micropolar-CassonCarreau nanofluids flow over thin needle is discussed. Flow model and related coordinate systems are analyzed. A schematic diagram associated with the concerned problem is shown in figure 1.

In current paper, we have following restrictions: 


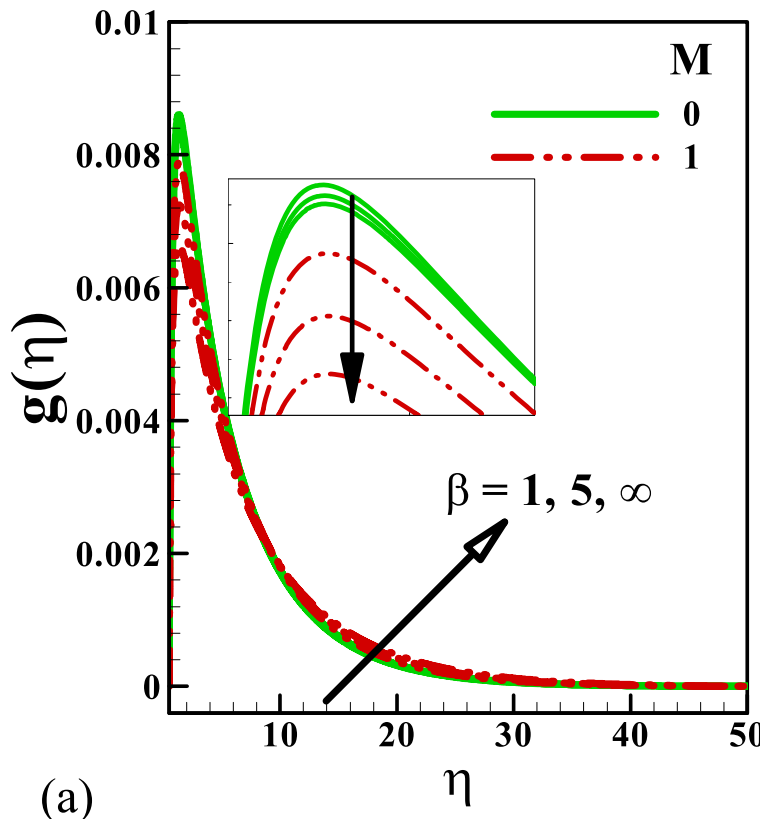

(a)

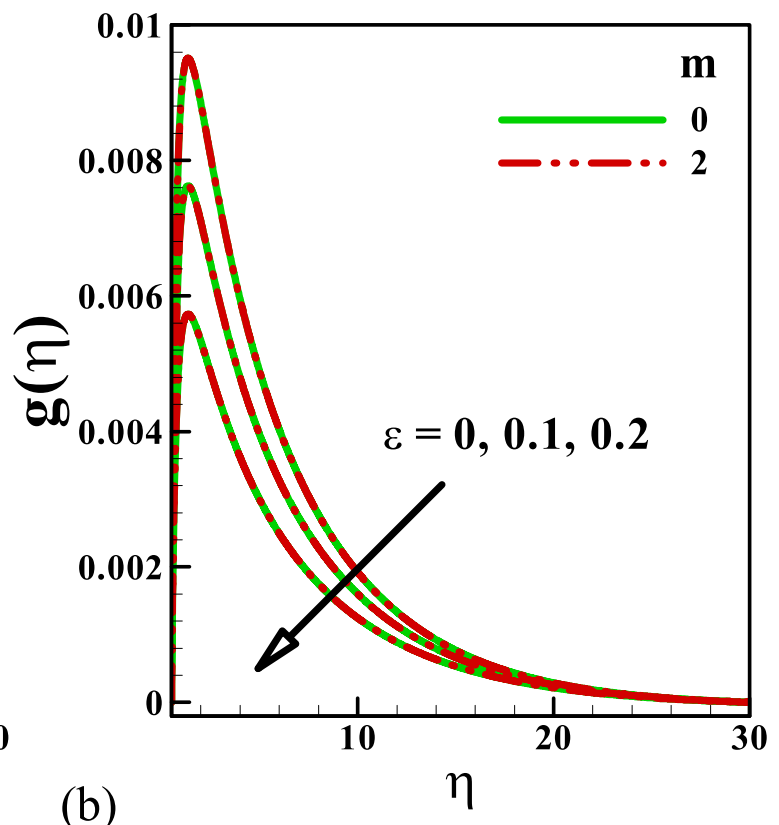

(b)

Figure 5. Outcomes of $g(\eta)$ versus (a) $\beta, M$ (b) $m$, $\varepsilon$.

(i) Thickness of needle is comparable/smaller than that of thermal and momentum boundary-layers over it.

(ii) Influence of curvature in transverse-direction has been prominent.

(iii) Pressure-gradient along thin needle is ignored i.e. $\frac{\partial p}{\partial x}=0$.

(iv) Ohmic heating and viscous dissipation impacts are considered.

(v) Arrhenius pre-exponential factor law is introduced.

(vi) Robinson's conditions are implemented.

(vii) Catteneo Christov double diffusion theory is applied.

(viii) Micropolar fluid model is applied.

(ix) Casson and Carreau fluid models are implemented.

(x) Buongiorno model is implemented.

(xi) Electromagneto hydrodynamic flow model is included.

Under the above assumptions, the resulting equations of non-Newtonian nanofluids flow over thin needle are

$$
\begin{gathered}
\frac{\partial}{\partial x}(r u)+\frac{\partial}{\partial r}(r v)=0, \\
u \frac{\partial u}{\partial x}+v \frac{\partial u}{\partial r}=\left(\frac{\mu_{f}+k}{\rho_{f}}\right)\left(1+\frac{1}{\beta}\right) \\
\times\left\{\begin{array}{l}
\left(\frac{1}{r} \frac{\partial u}{\partial r}+\frac{\partial^{2} u}{\partial r^{2}}\right)\left[1+\Gamma^{2}\left(\frac{\partial u}{\partial r}\right)^{2}\right]^{\frac{n-1}{2}} \\
+(n-1) \Gamma^{2}\left(\frac{\partial u}{\partial r}\right)^{2}\left(\frac{\partial^{2} u}{\partial r^{2}}\right)\left[1+\Gamma^{2}\left(\frac{\partial u}{\partial r}\right)^{2}\right]^{\frac{n-3}{2}}
\end{array}\right\} \\
+g^{*} \beta_{T}\left(T-T_{\infty}\right)+\frac{k}{\rho_{f}} \frac{\partial N}{\partial r}+\frac{\sigma_{f}}{\rho_{f}}\left(E_{0} B_{0}-B_{0}^{2} u\right) \\
\rho_{f} j\left(u \frac{\partial N}{\partial x}+v \frac{\partial N}{\partial r}\right)=\gamma \frac{\partial^{2} N}{\partial r^{2}}-k\left(2 N+\frac{\partial u}{\partial r}\right)
\end{gathered}
$$

$$
\begin{aligned}
& u \frac{\partial T}{\partial x}+v \frac{\partial T}{\partial r}+\Omega_{1} \\
& \quad \times\left(\begin{array}{l}
u^{2} \frac{\partial^{2} T}{\partial x^{2}}+v^{2} \frac{\partial^{2} T}{\partial r^{2}}+2 u v \frac{\partial^{2} T}{\partial r \partial x}+u \frac{\partial u}{\partial x} \frac{\partial T}{\partial x} \\
+u \frac{\partial v}{\partial x} \frac{\partial T}{\partial r}+v \frac{\partial u}{\partial r} \frac{\partial T}{\partial x}+v \frac{\partial v}{\partial r} \frac{\partial T}{\partial r}
\end{array}\right) \\
& =\frac{\alpha_{f}}{r} \frac{\partial}{\partial r}\left(r \frac{\partial T}{\partial r}\right)+\frac{\left(\rho c_{p}\right)_{p}}{\left(\rho c_{p}\right)_{f}}\left[D_{B} \frac{\partial C}{\partial r} \frac{\partial T}{\partial r}+\frac{D_{T}}{T_{\infty}}\left(\frac{\partial T}{\partial r}\right)^{2}\right] \\
& +\left(1+\frac{1}{\beta}\right) \frac{\left(\mu_{f}+k\right)}{\left(\rho c_{p}\right)_{f}}\left[1+\Gamma^{2}\left(\frac{\partial u}{\partial r}\right)^{2}\right]^{\frac{n-1}{2}}\left(\frac{\partial u}{\partial r}\right)^{2} \\
& +\frac{\sigma_{f}}{\left(\rho c_{p}\right)_{f}}\left(u^{2} B_{0}^{2}-E_{0}^{2}\right)
\end{aligned}
$$

$$
\begin{aligned}
& u \frac{\partial C}{\partial x}+v \frac{\partial C}{\partial r}+\Omega_{2} \\
& \times\left(\begin{array}{l}
u^{2} \frac{\partial^{2} C}{\partial x^{2}}+v^{2} \frac{\partial^{2} C}{\partial r^{2}}+2 u v \frac{\partial^{2} C}{\partial r \partial x}+u \frac{\partial u}{\partial x} \frac{\partial C}{\partial x} \\
+u \frac{\partial v}{\partial x} \frac{\partial C}{\partial r}+v \frac{\partial u}{\partial r} \frac{\partial C}{\partial x}+v \frac{\partial v}{\partial r} \frac{\partial C}{\partial r}
\end{array}\right) \\
& =\frac{D_{B}}{r} \frac{\partial}{\partial r}\left(r \frac{\partial C}{\partial r}\right)+\frac{D_{T}}{T_{\infty}} \frac{1}{r} \frac{\partial}{\partial r}\left(r \frac{\partial T}{\partial r}\right)-K^{*}
\end{aligned}
$$

Here, $u$ and $v$ are the axial and radial components of velocity, $(x, r)$ cylindrical coordinates, $\rho_{f}$ density of fluid, $\mu_{f}$ fluid dynamic viscosity, $k$ vortex viscosity of micro-polar fluid, $\beta$ Casson fluid parameter, $n$ power law index, $\Gamma$ time constant, $\sigma_{f}$ Stefan Boltzmann constant, $k^{*}$ mean absorption coefficient, $\Omega_{1}$ and $\Omega_{2}$ thermal and solutal relaxation times correspondingly, $(T, C)$ temperature and concentration of nanoparticles respectively and $\left(T_{\infty}, C_{\infty}\right)$ 

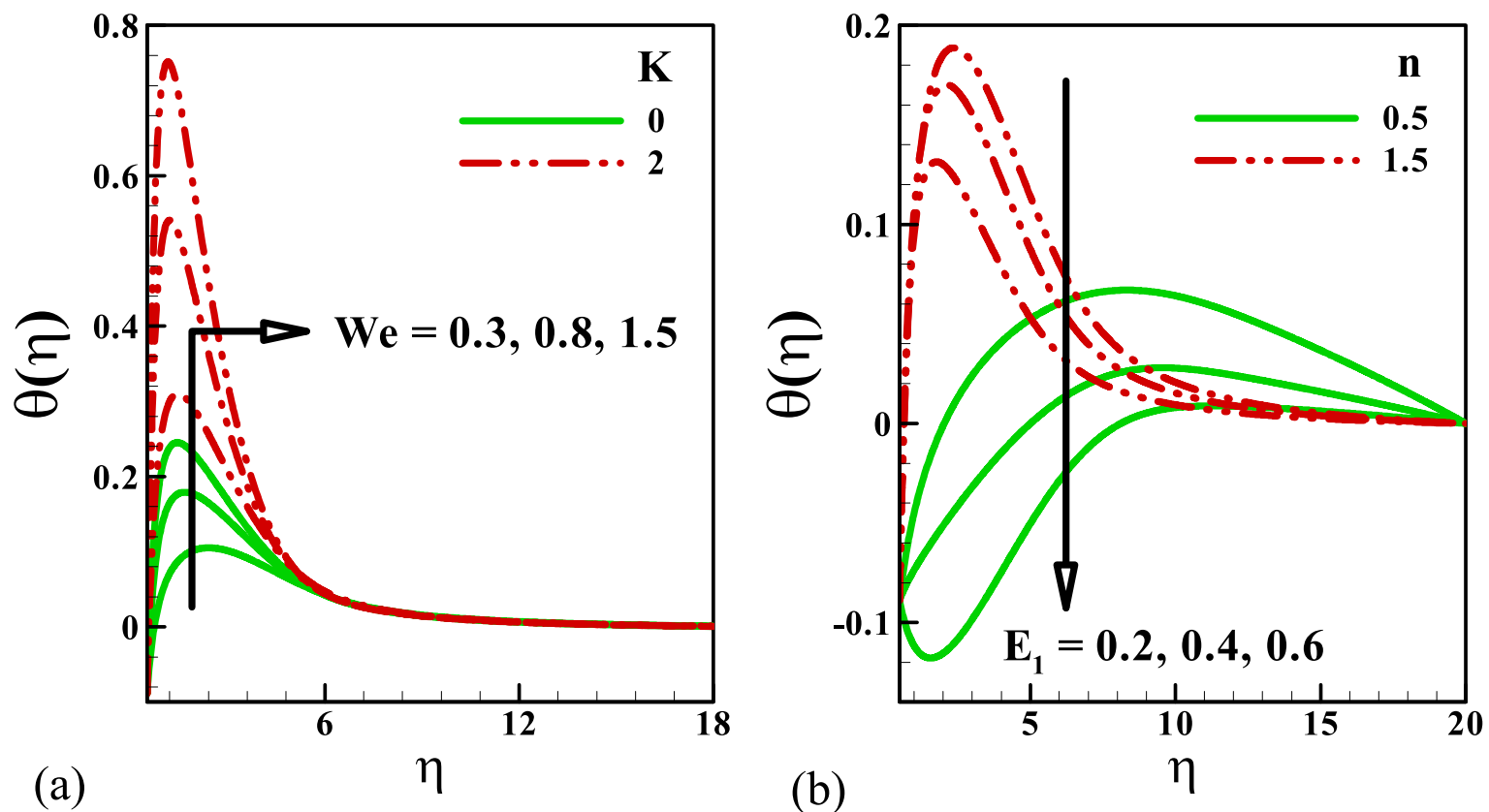

Figure 6. Outcomes of $\theta(\eta)$ versus (a) $W e, K$ (b) $E_{1}, n$.

ambient temperature and concentration of nanoparticles respectively. We assume that the spin gradient viscosity $(\gamma)$ is addressed by

$$
\gamma=\left(\mu_{f}+\frac{k}{2}\right) j=\mu_{f}\left(1+\frac{K}{2}\right) j
$$

In which $K=\frac{k}{\mu_{f}}$ shows material parameter, $\alpha_{f}$ thermal diffusivity, $g$ gravitational acceleration, $\beta_{T}$ thermal expansion coefficient, $D_{B}$ coefficient of mass diffusion, $E_{0}$ electric field strength and $B_{0}$ magnetic field strength.

In concentration expression (5), the expression $K^{*}=$ $k_{r}^{2}\left(\frac{T}{T_{\infty}}\right)^{m} \exp \left(-\frac{E_{a}}{k_{B} T}\right)$ expresses the Arrhenius Pre-exponential factor law. Here $k_{r}^{2}$ stands for chemical reaction rate constant, $E_{a}$ for activation energy and $k_{B}=1.38 \times$ $10^{-23} \mathrm{~J} \mathrm{~K}^{-1}$ for Boltzman constant. Employing above information, equation (5) becomes

$$
\begin{aligned}
& u \frac{\partial C}{\partial x}+v \frac{\partial C}{\partial r}+\Omega_{2} \\
& \times\left(\begin{array}{l}
u^{2} \frac{\partial^{2} C}{\partial x^{2}}+v^{2} \frac{\partial^{2} C}{\partial r^{2}}+2 u v \frac{\partial^{2} C}{\partial r \partial x}+u \frac{\partial u}{\partial x} \frac{\partial C}{\partial x} \\
+u \frac{\partial v}{\partial x} \frac{\partial C}{\partial r}+v \frac{\partial u}{\partial r} \frac{\partial C}{\partial x}+v \frac{\partial v}{\partial r} \frac{\partial C}{\partial r}
\end{array}\right) \\
& =\frac{D_{B}}{r} \frac{\partial}{\partial r}\left(r \frac{\partial C}{\partial r}\right)+\frac{D_{T}}{T_{\infty}} \frac{1}{r} \frac{\partial}{\partial r}\left(r \frac{\partial T}{\partial r}\right) \\
& -\underbrace{k_{r}^{2}\left(\frac{T}{T_{\infty}}\right)^{m} \exp \left(-\frac{E_{a}}{k_{B} T}\right)\left(C-C_{\infty}\right)}
\end{aligned}
$$

Boundary conditions for current problem are

$$
\begin{aligned}
& \left.u\right|_{r=R}=u_{w},\left.v\right|_{r=R}=0,\left.N\right|_{r=R}=-\left.m \frac{\partial u}{\partial r}\right|_{r=R} \\
& \left.-k \frac{\partial T}{\partial r}=\left.h_{1}\left(T_{s}-T\right)\right|_{r=R},-k \frac{\partial C}{\partial r}=\left.h_{2}\left(C_{s}-C\right)\right|_{r=R}\right\} \\
& \left.u\right|_{r \rightarrow \infty}=u_{\infty},\left.N\right|_{r \rightarrow \infty} \rightarrow 0,\left.T\right|_{r \rightarrow \infty} \rightarrow T_{\infty}=c_{1} x \\
& +T_{0},\left.C\right|_{r \rightarrow \infty} \rightarrow C_{\infty}=d_{1} x+C_{0},
\end{aligned}
$$

here $h_{1}$ and $h_{2}$ stand for heat and mass transfer coefficients, $T_{s}=c x+T_{0}, C_{s}=d x+C_{0}$ for surface temperature-concentration and $T_{\infty}=c_{1} x+T_{0}, C_{\infty}=d_{1} x+C_{0}$ for ambient temperature-concentration respectively.

The suitable transformations are

$$
\left.\begin{array}{l}
u=2 U f^{\prime}(\eta), v=-\frac{v_{f}}{r} f+\eta \frac{v_{f}}{r} f^{\prime}(\eta), N=\frac{r U^{2}}{v_{f} x} g(\eta), \\
\theta(\eta)=\frac{T-T_{\infty}}{T_{s}-T_{0}}, \phi(\eta)=\frac{C-C_{\infty}}{C_{s}-C_{0}}, \eta=\frac{U r^{2}}{v_{f} x}
\end{array}\right\}
$$

where velocities $u$ and $v$ satisfy equation (1) identically. By letting $\eta=A$ in the equation (6), we have $R(x)=\left(\frac{A v x}{U}\right)^{1 / 2}$ is the surface shape of axisymmetric body. Using equation (9) in equations (2)-(5) and (8), we get

$$
\begin{aligned}
& (1+K)\left(1+\frac{1}{\beta}\right)\left\{\begin{array}{l}
\left(2 f^{\prime \prime}+2 \eta f^{\prime \prime \prime}\right)\left(1+16 W e^{2}\right)^{\frac{n-1}{2}} \\
+16(n-1) W e^{2}\left(f^{\prime \prime}+2 \eta f^{\prime \prime \prime}\right)\left(1+16 W e^{2}\right)^{\frac{n-3}{2}}
\end{array}\right\} \\
& +f f^{\prime \prime}+\frac{1}{4}\left(\frac{G r}{\operatorname{Re}_{x}^{2}}\right) \theta+\frac{1}{4} K\left(g+2 \eta g^{\prime}\right)+\frac{1}{4} M\left(E_{1}-2 f^{\prime}\right)=0
\end{aligned}
$$



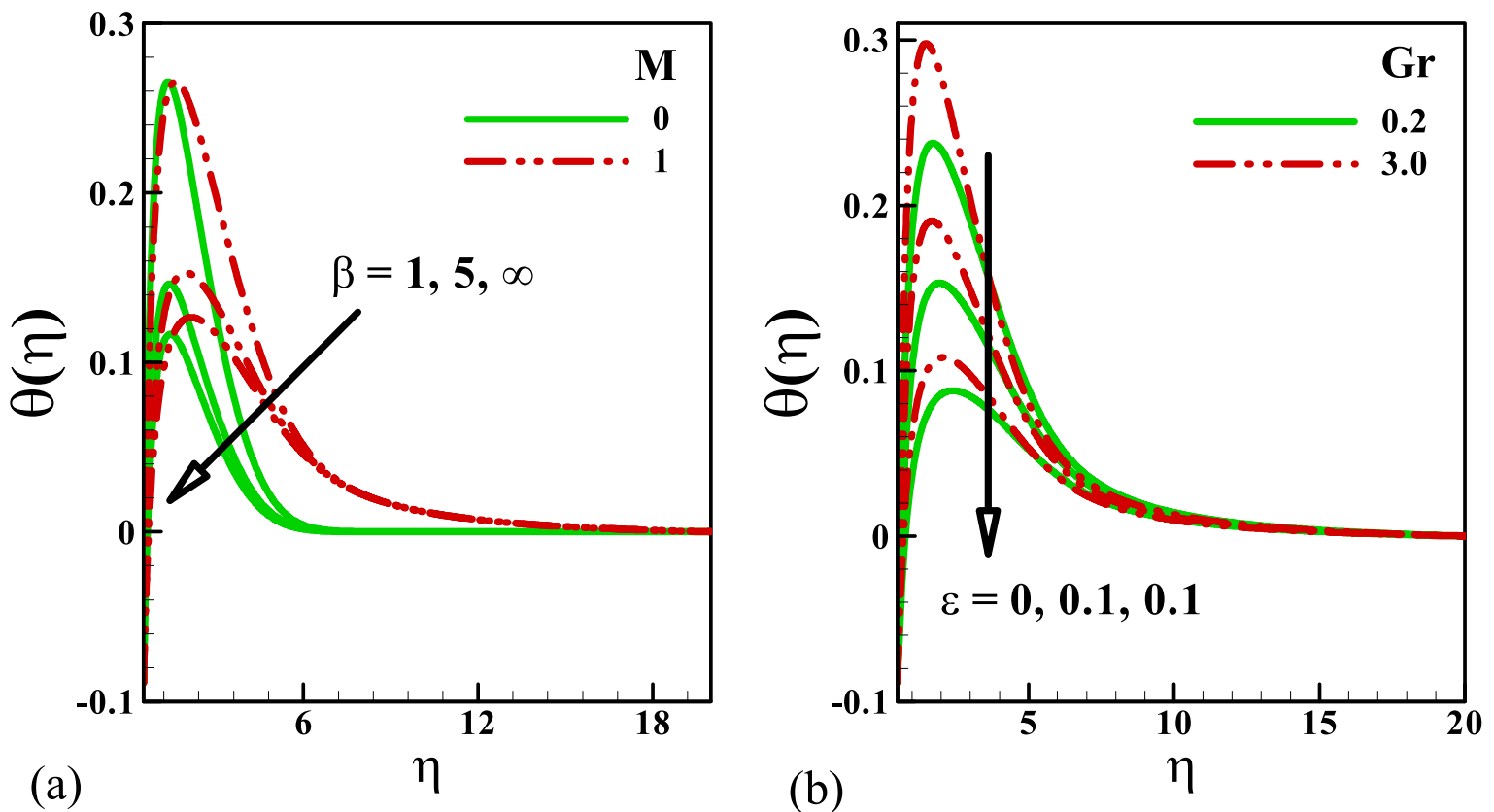

Figure 7. Outcomes of $\theta(\eta)$ versus (a) $\beta, M$ (b) $G_{r}, \varepsilon$.

$$
\left(1+\frac{K}{2}\right)\left(4 \eta^{2} g^{\prime \prime}+6 \eta g^{\prime}\right)+\eta\left(2 f g^{\prime}+g f^{\prime}\right)
$$$$
+f g-2 K B\left(g+2 f^{\prime \prime}\right)=0
$$

$$
\begin{aligned}
& 2 \theta^{\prime}+2 \eta \theta^{\prime \prime}+\operatorname{Pr} f \theta^{\prime} \\
& -\operatorname{Pr} \Gamma_{1}\left\{\begin{array}{l}
4 \eta^{2}\left(f^{\prime}\right)^{2} \theta^{\prime \prime}+4 \eta\left(f^{\prime}\right)^{2} \theta^{\prime \prime}-4 \eta f f^{\prime} \theta^{\prime \prime} \\
+2 \eta \Lambda f f^{\prime} \theta^{\prime \prime}-3 \eta f^{2} \theta^{\prime}+\frac{2}{\eta} f^{2} \theta^{\prime}
\end{array}\right\} \\
& +2 \operatorname{Pr} N b \eta \theta^{\prime} \phi^{\prime}+2 \operatorname{Pr} N t \eta\left(\theta^{\prime}\right)^{2} \\
& +8\left(1+\frac{1}{\beta}\right)(1+K) \eta B r\left(1+16 W e^{2}\right)^{\frac{n-1}{2}}\left(f^{\prime \prime}\right)^{2} \\
& +\operatorname{Br} M\left\{2\left(f^{\prime}\right)^{2}-\frac{1}{2} E_{1}^{2}\right\}=0
\end{aligned}
$$

$$
\begin{aligned}
& 2 \phi^{\prime}+2 \eta \phi^{\prime \prime}+S c f \phi^{\prime} \\
& -S c \Gamma_{2}\left\{\begin{array}{l}
4 \eta^{2}\left(f^{\prime}\right)^{2} \phi^{\prime \prime}+4 \eta\left(f^{\prime}\right)^{2} \phi^{\prime \prime}-4 \eta f f^{\prime} \phi^{\prime \prime} \\
+2 \eta \Lambda f f^{\prime} \phi^{\prime \prime}-3 \eta f^{2} \phi^{\prime}+\frac{2}{\eta} f^{2} \phi^{\prime}
\end{array}\right\} \\
& +2\left(\frac{N t}{N b}\right)\left(\theta^{\prime}+\eta \theta^{\prime \prime}\right)-\frac{1}{2} \lambda S c(1+\delta \theta)^{m} \exp \left[-\frac{E}{(1+\delta \theta)}\right] \phi=0
\end{aligned}
$$

with

$$
\left.\begin{array}{l}
f^{\prime}(A)=\frac{\varepsilon}{2}, f(A)=0, g(A)=-4 m f^{\prime \prime}(A), \\
\theta^{\prime}(A)=-\frac{1}{2} \beta_{1}\left[1-S_{t}-\theta(A)\right], \phi^{\prime}(A)=-\frac{1}{2} \beta_{2}\left[1-S_{c}-\phi(A)\right], \\
f^{\prime}(\infty)=\frac{1}{2}(1-\varepsilon), g^{\prime}(\infty)=0, \quad \theta(\infty) \rightarrow 0, \quad \phi(\infty) \rightarrow 0
\end{array}\right\}
$$

In the above expressions, the involved interesting parameters are defined by

$$
\left.\begin{array}{l}
\operatorname{Re}_{x}=\frac{U x}{v_{f}}, W e=\left(\frac{\Gamma U}{x}\right) \operatorname{Re}_{x}, K=\frac{k}{\mu_{f}}, E_{1}=\frac{U_{0}}{E B_{0}}, M=\frac{\sigma_{f} B_{0}^{2} x}{\rho_{f} U}, S c=\frac{v_{f}}{D_{B}}, B=\frac{r^{2}}{j}, \\
\delta=\frac{T_{s}-T_{0}}{T_{\infty}}, G r=\frac{g^{*} \beta\left(T_{s}-T_{0}\right) x^{3}}{v_{f}^{2}}, \Gamma_{1}=\frac{\Omega_{1} U}{x}, \Gamma_{2}=\frac{\Omega_{2} U}{x}, \operatorname{Pr}=\frac{v_{f}}{\alpha_{f}}, \Lambda=\frac{r}{x}, \\
N t=\frac{\tau D_{T}\left(T_{s}-T_{0}\right)}{v_{f} T_{\infty}}, N b=\frac{\tau D_{B}\left(C_{s}-C_{0}\right)}{v_{f}}, E_{c}=\frac{U^{2}}{\left(c_{p}\right)_{f}\left(T_{s}-T_{0}\right)}, B r=M \operatorname{Pr}, \\
E=\frac{E_{a}}{k_{B} T_{\infty}}, \lambda=\frac{x k_{r}^{2}}{U}, \varepsilon=\frac{u_{w}}{U}, S_{t}=\frac{c_{1}}{c}, S_{c}=\frac{d_{1}}{d}, \beta_{1}=\frac{h_{1}}{k\left(\frac{U r}{v x}\right)}, \beta_{2}=\frac{h_{2}}{k\left(\frac{U r}{v x}\right)}
\end{array}\right\}
$$



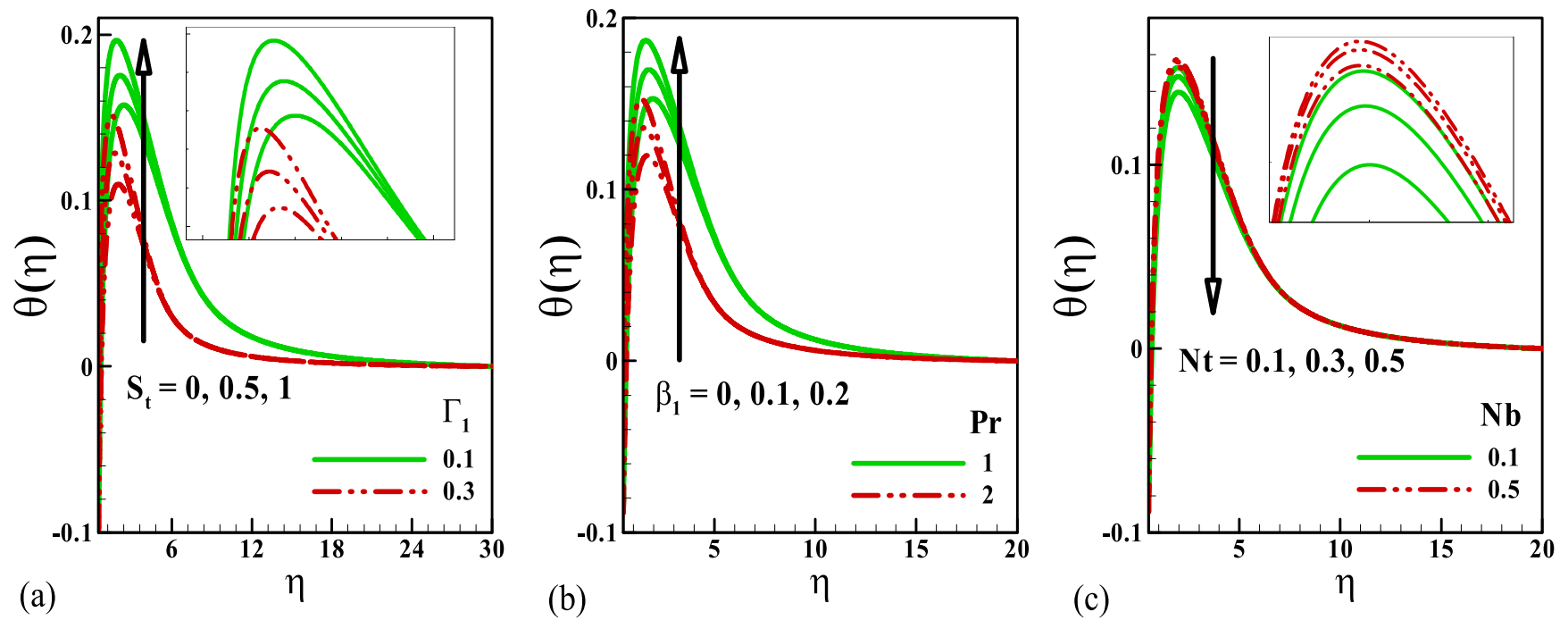

Figure 8. Outcomes of $\theta(\eta)$ versus (a) $S_{t}, \Gamma_{1}$ (b) $\beta_{1}, \operatorname{Pr}$ (c) $N t, N b$.

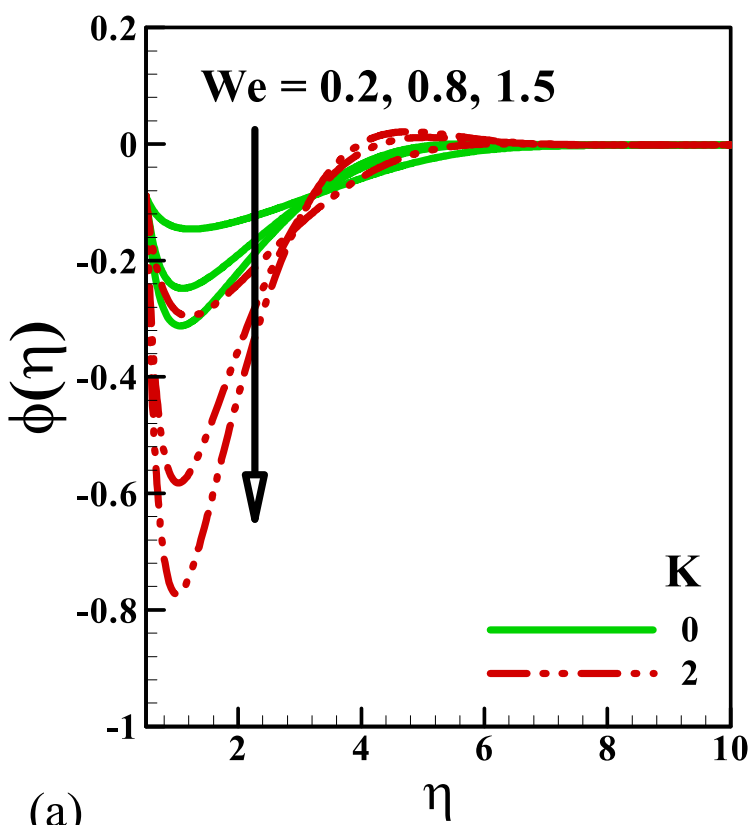

(a)

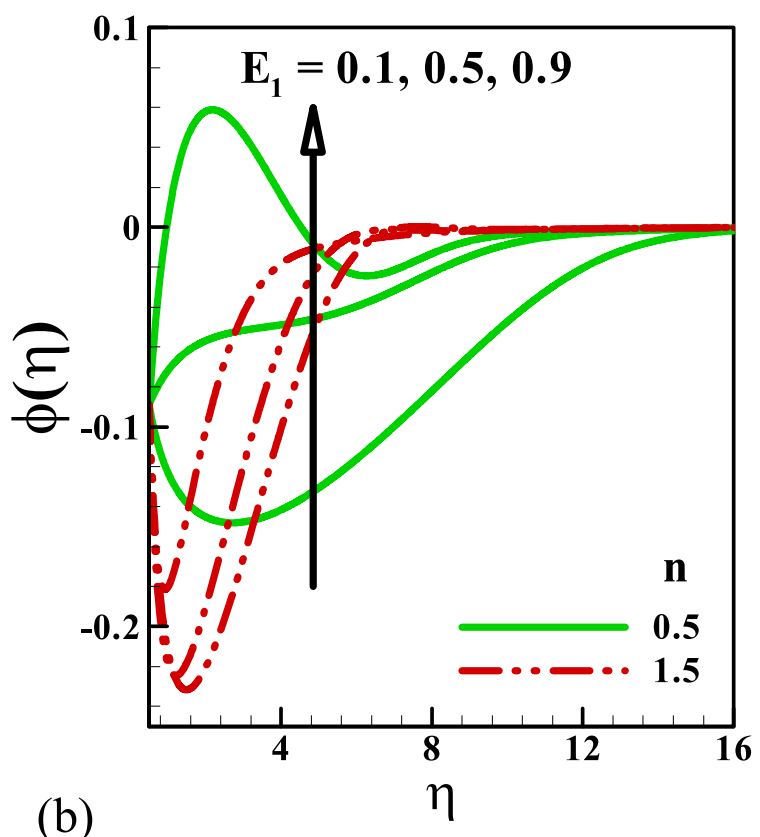

(b)

Figure 9. Outcomes of $\phi(\eta)$ versus (a) $W e, K$ (b) $E_{1}, n$.

In which $K$ stands for material parameter, We for Weissenberg parameter, $G r$ for thermal Grashof of number, $\operatorname{Re}_{x}$ for Reynolds number, $M$ for Hartman number, $E_{1}$ for electric parameter, Pr for Prandtl number, $\Lambda$ for non-dimensional parameter, $N t$ for thermophoresis parameter, $N b$ for Brownian movement parameter, $\mathrm{Br}$ for Brinkman number, $B$ for micro-inertia density parameter, $S c$ for Schmidt number, $\Gamma_{1}$ and $\Gamma_{2}$ for Deborah numbers in terms of relaxation and retardation times respectively, $\delta$ for temperature difference parameter, $E$ for dimensionless activation energy, $\beta_{1}$ and $\beta_{2}$ for thermal and solutal Biot numbers correspondingly and $S_{t}$ and $S_{c}$ for thermal and solutal stratified parameters correspondingly.
The dimensionless local skin friction and wall couple stresses are defined by

$\operatorname{Re}_{x}^{\frac{1}{2}} C_{f x}=4(1+K)\left(1+\frac{1}{\beta}\right) A^{\frac{1}{2}}\left[1+\left\{W e f^{\prime \prime}(A)\right\}^{2}\right]^{\frac{n-1}{2}} f^{\prime \prime}(A)$

$$
\operatorname{Re}_{x}^{\frac{1}{2}} C_{g x}=\left(1+\frac{K}{2}\right)\left(1+\frac{1}{\beta}\right)\left[A^{\frac{1}{2}} g(A)+2 A^{\frac{3}{2}} g_{\eta}(A)\right]
$$

in which the local Reynolds number is defined by $\operatorname{Re}_{x}=\frac{U x}{v}$. 

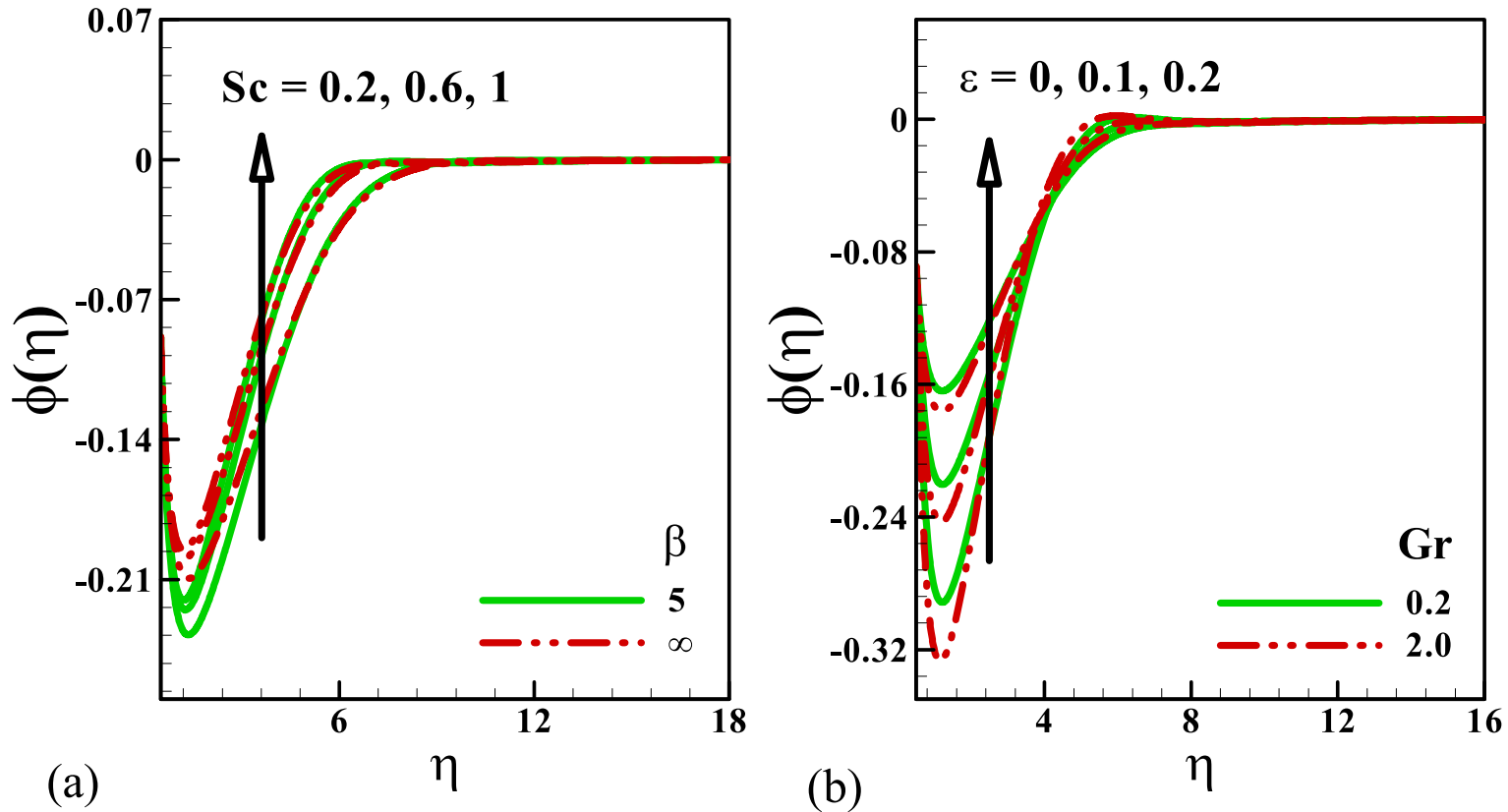

Figure 10. Outcomes of $\phi(\eta)$ versus (a) $S c, \beta$ (b) $\varepsilon, G r$.
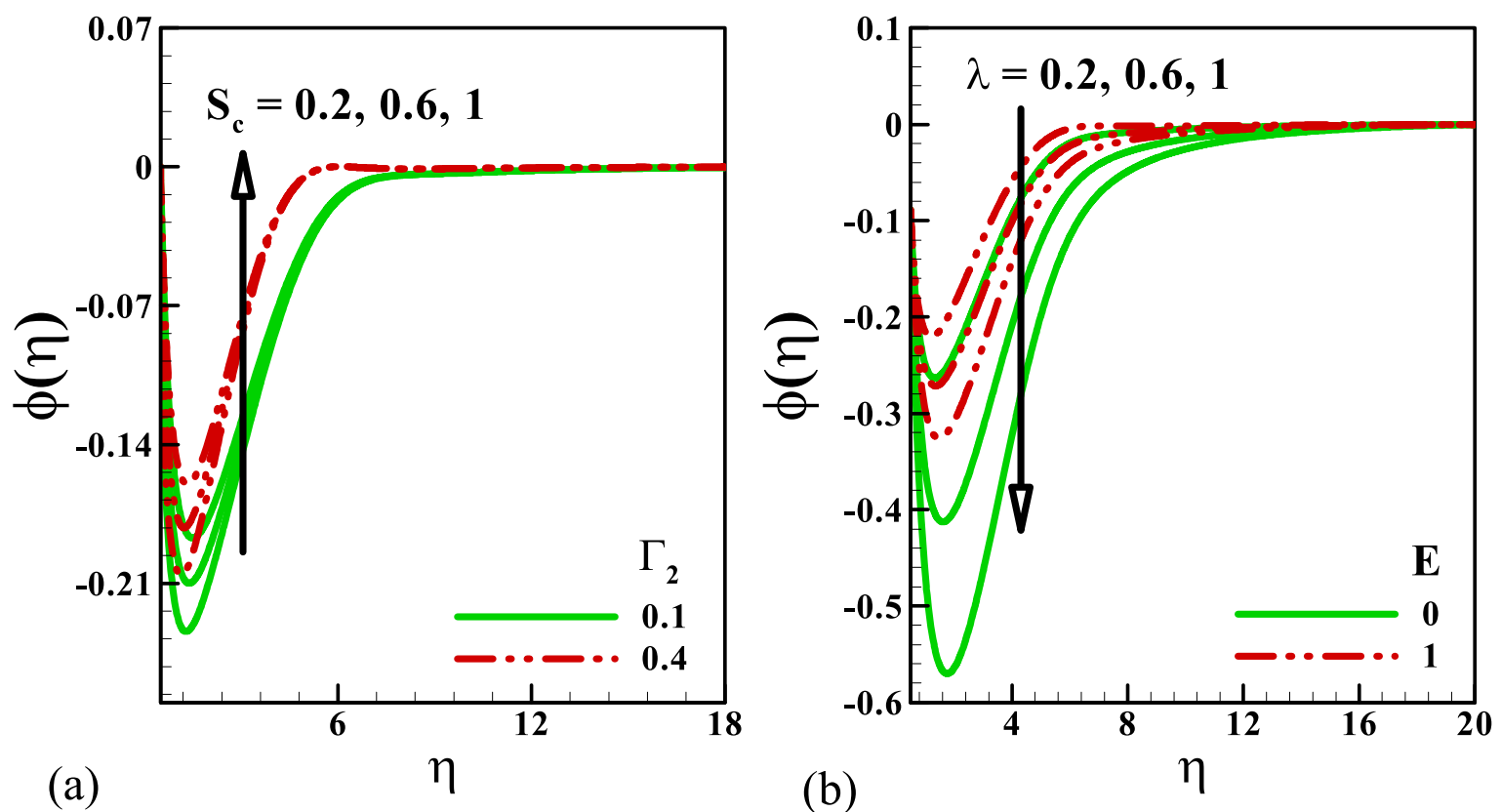

Figure 11. Outcomes of $\phi(\eta)$ versus (a) $S_{c}, \Gamma_{2}$ (b) $\lambda, E$.

\section{Numerical outcomes and discussion}

Figures 2(a), (b) shows the consequences of Weissenberg number $W e$, material parameter $K$ and electric parameter $E_{1}$ on velocity profile $f^{\prime}$. From the figure $2(a)$, it is seen that velocity profile is diminishing by the variations of Weissenberg number and material parameter. From the figure 2(b), it is also seen that velocity field is decayed for varying electric parameter for both $(n=0.5 \& 1.5)$. Figures 3(a), (b) illustrates the behavior of Casson fluid number $\beta$, thermal Grashof number $G r$ and Hartman number $M$ on velocity profile $f^{\prime}$. It is cleared that the velocity field $f^{\prime}$ is reduced for growing values of $\beta$ and $M$. Figures 4(a), (b) designates the influence of Weissenberg number $W e$, material parameter $K$ and temperature difference parameter $\delta$ against velocity profile. It is viewed that velocity is decayed for Weissenberg number We while it shows reverse behavior for material parameter $K$ and temperature difference parameter $\delta$ for both $(n=0.5 \& 1.5)$. Figures 5(a), (b) is displayed the characteristics of velocity field for Casson fluid number $\beta$, Hartman number $M, \varepsilon$ and ( $m=0 \& 2)$. It is noted that velocity field reduces for $M$ and $\varepsilon$. The effects of Weissenberg number We, material parameter 

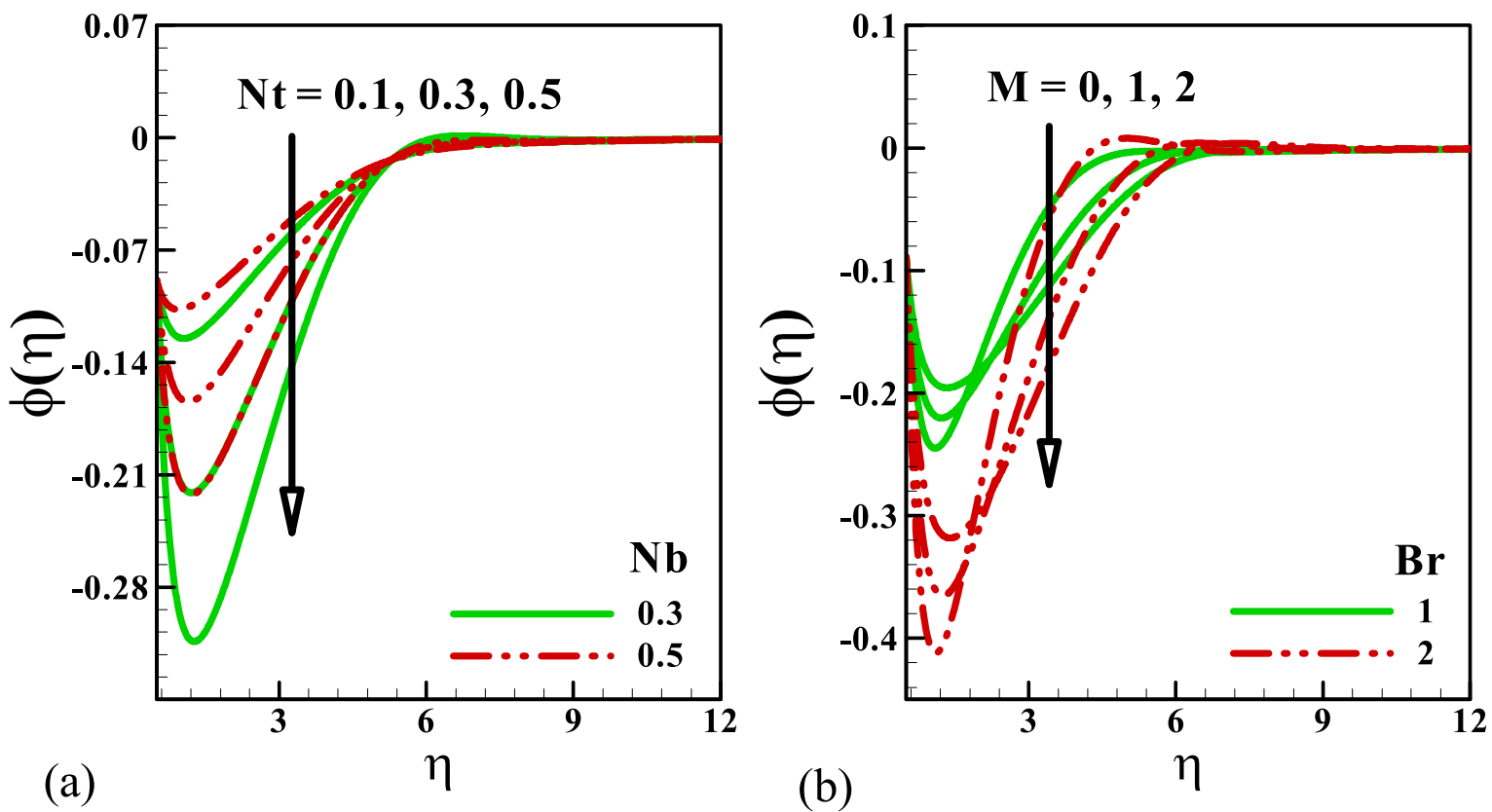

Figure 12. Outcomes of $\phi(\eta)$ versus (a) $N t, N b$ (b) $M, B r$.
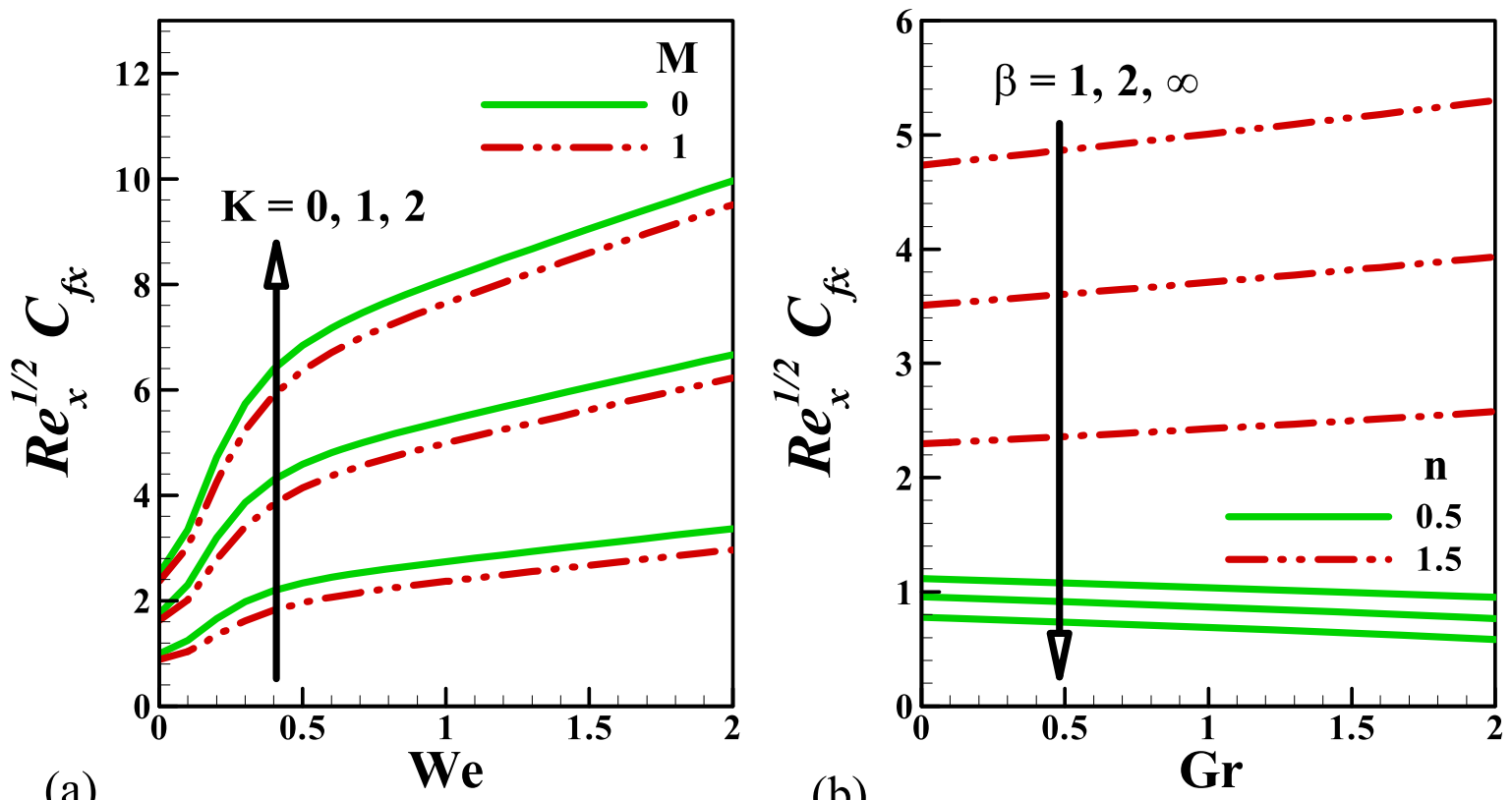

Figure 13. Outcomes of skin friction ( $x$-direction) (a) We, $K$, and $M$ (b) $G r, n$, and $\beta$.

$K$ and electric parameter $E_{1}$ on temperature profile $\theta$ are explored in figures 6(a), (b). It is apparent that temperature profile is enlarged for Weissenberg number and material parameter for both ( $n=0.5 \& 1.5$ ). Figures 7(a), (b) signifies the behavior of the thermal Grashof number $G r$, Hartman number $M$, Casson fluid parameter $\beta$ and $\varepsilon$ on temperature profile $\theta$. It is evaluated that temperature of fluid $\theta$ is enhanced for Hartman number and thermal Grashof number. Figures 8 (a)-(c) delineates the impacts of Deborah number $\Gamma_{1}$, thermal Biot number $\beta_{1}$, thermal stratification parameter $S_{t}$, thermophoresis parameter $N t$, Prandtl number $\mathrm{Pr}$ and
Brownian motion parameter $\mathrm{Nb}$ on temperature profile $\theta$. It is visualized that for the intensifying values of thermal stratification parameter and thermal Biot number $\beta_{1}$, the temperature field enhances. Figures $9(a)$, (b) discloses the characteristics of Weissenberg number We, material parameter $K$ and electric parameter $E_{1}$ against the concentration of nanoparticles $\phi$. It is perceived that concentration of nanoparticles $\phi$ is augmented with Weissenberg number We and material parameter $K$ for $(n=0.5 \& 1.5)$. The features of the Schmidt number $S c$, Grashof number $G r$, Casson fluid parameter $\beta$ and $\varepsilon$ against the concentration of nanoparticles $\phi$ are 


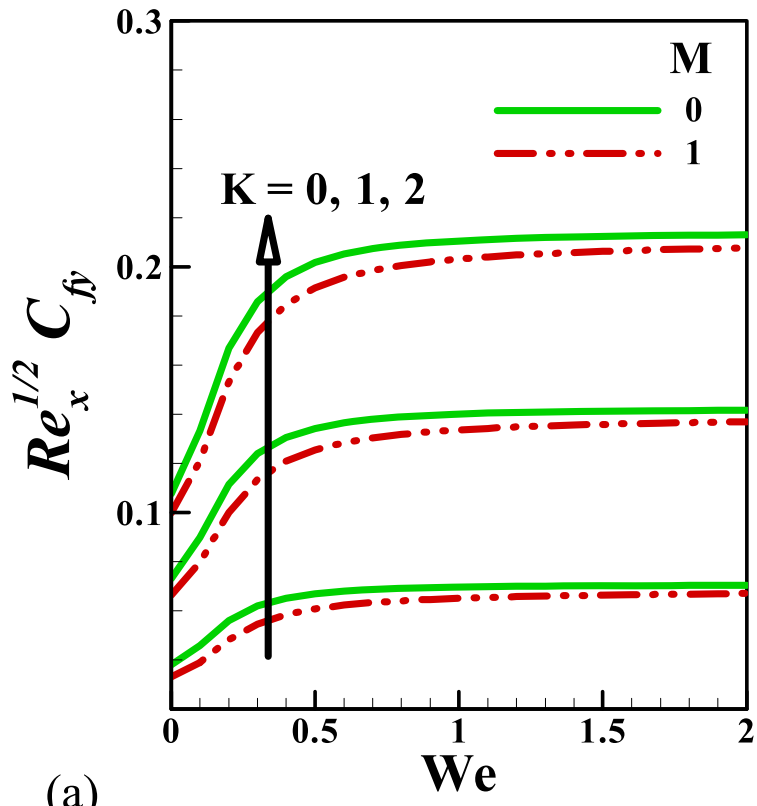

(a)

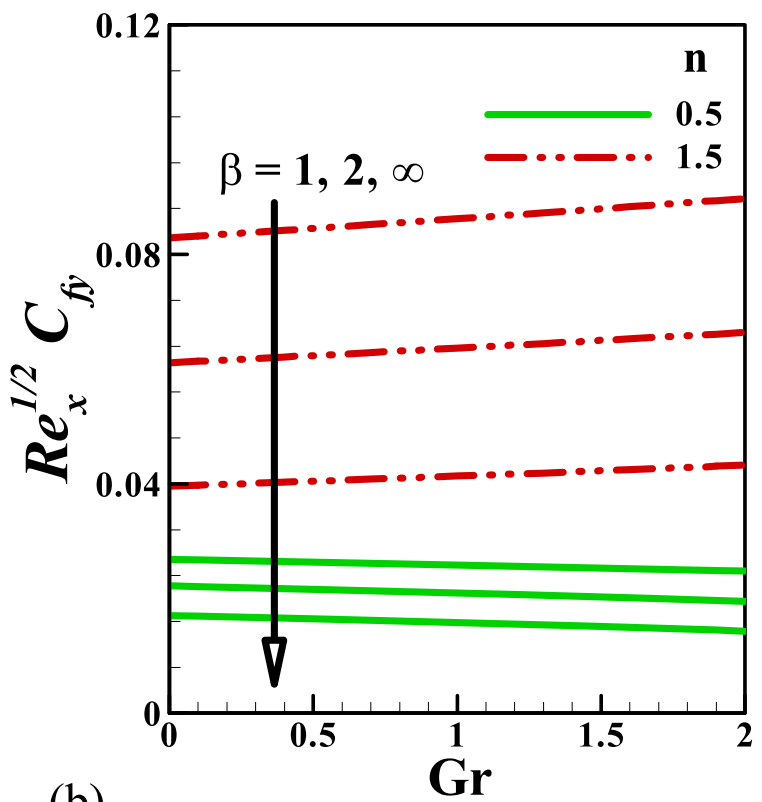

(b)

Figure 14. Outcomes of skin friction (y-direction) (a) $W e, K$, and $M$ (b) $G r, n$, and $\beta$.

Table 1. Numerical values of skin friction for various values of physical parameters.

\begin{tabular}{ccccccc}
\hline$K$ & We & $\beta$ & $M$ & $n$ & $\mathrm{Re}_{x}^{1 / 2} C_{f x}$ & $\mathrm{Re}_{x}^{1 / 2} C_{f y}$ \\
\hline 1 & 0.5 & 2 & 1 & 1.5 & 4.98998 & 0.075358 \\
2 & & & & & 7.751786 & 0.158443 \\
3 & & & & & 10.54131 & 0.244488 \\
5 & 0.0 & & & & 10.55898 & 0.333666 \\
& 0.8 & & & & 18.32921 & 0.438883 \\
& 1.4 & & & & 21.32474 & 0.449830 \\
& 0.5 & 1 & & & 21.75952 & 0.565547 \\
& 5 & & & 12.79731 & 0.332377 \\
& 10 & & & 11.68048 & 0.303307 \\
& 3 & 0.0 & & 15.12571 & 0.390802 \\
& & 0.4 & & 14.77392 & 0.382630 \\
& & 0.8 & & 14.44473 & 0.374891 \\
& & 1.0 & 0.5 & 0.751600 & 0.033344 \\
& & & 1.0 & 5.282363 & 0.188525 \\
& & & 1.5 & 14.63049 & 0.360251 \\
\hline
\end{tabular}

captured in figures $10(\mathrm{a}),(\mathrm{b})$. It has been scrutinized that the concentration profile of nanoparticles is decayed for distinct values of Schmidt number. Figures 11(a), (b) depicts the nature of solutal stratification parameter $S_{c}$, Deborah number $\Gamma_{2}, \lambda$ and activation energy $E$ against the concentration of nanoparticles $\phi$. It is deliberated from these drawn lines that the concentration of nanoparticles $\phi$ is upgraded for solutal stratification parameter. The consequences of Hartman number $M$, thermophoresis parameter $N t$, Brownian motion parameter $\mathrm{Nb}$ and Brinkman number $\mathrm{Br}$ against the concentration profile $\phi$ are displayed in figures 12(a), (b). It is watched from the curves that the growing values of Hartman number and thermophoresis parameter produces enhancement in concentration profile of nanoparticles. Figures 13(a), (b) explains the outcomes of Hartman number $M$, Casson fluid parameter $\beta$, Weissenberg number $W e$, material parameter $K$ and Grashof number $G r$ on skin friction $\operatorname{Re}_{x}^{\frac{1}{2}} C_{f x}$. The skin friction $\operatorname{Re}_{x}^{\frac{1}{2}} C_{f x}$ increases by expanding values of Weissenberg number and material parameter while reverse situation is watched for Casson fluid parameter for both $(n=0.5 \& 1.5)$. Figures 14(a), (b) elucidates the results of Hartman number $M$, Weissenberg number $W e$, Casson fluid parameter $\beta$, material parameter $K$ and Grashof number $G r$ on skin friction $\operatorname{Re}_{x}^{\frac{1}{2}} C_{f y}$. The skin friction $\operatorname{Re}_{x}^{\frac{1}{2}} C_{f y}$ upsurges by escalating values of material parameter. In addition, the skin friction $\operatorname{Re}_{x}^{\frac{1}{2}} C_{g x}$ is decayed for Casson fluid parameter for both ( $n=0.5 \& 1.5)$. Numerical outcomes of skin frictions against different values of prominent parameters like $K, W e, \beta, M$ and $n$ are shown in table 1 . Here the skin frictions are reduced for various values of $M$ while upsurges for larger estimations of $K$.

\section{Conclusions}

Electromagnetohydrodynamic (EMHD) flow of non-Newtonian nanoliquids over thin needle with Robinson's conditions and Arrhenius pre-exponential factor law is studied. The relevant partial differential equations are reformulated into the system of ordinary differential expressions by implementing appropriate transformations. Such obtained equations subject to boundary constraints are computed numerically by considering Runge-Kutta-Fehlberg method. With an enhancement in Hartman number, both velocities decay. The velocity field is upgraded for electric parameter. Temperature field enhances for larger thermal Biot number. The volumetric 
concentration of nanoparticles is decayed with Schmidt number. The concentration field upsurges with growing values of thermophoresis parameter while fall down with Brownian movement parameter.

\section{Conflict of interest}

The authors declare no conflict of interest.

\section{ORCID iDs}

Fazle Mabood (10) https://orcid.org/0000-0003-2698-8427

\section{References}

[1] Choi S U S and Eastman J A 1995 Enhancing thermal conductivity of fluids with nanoparticles ASME International Mechanical Engineering Congress \& Exposisition (San Francisco) (American Society of Mechanical Engineers)

[2] Buongiorno J 2006 Convective transport in nanofluids Journal of Heat Transfer 128 240-50

[3] Ali M, Sultan F, Khan W A, Shahzad M and Arif H 2020 Important features of expanding/contracting cylinder for Cross magneto-nanofluid flow Chaos, Solitons \& Fractals 133109656

[4] Na W, Shah N A, Tlili I and Siddique I 2020 Maxwell fluid flow between vertical plates with damped shear and thermal flux: free convection Chin. J. Phys. 65 367-76

[5] Ahmed A, Khan M and Ahmed J 2020 Mixed convective flow of Maxwell nanofluid induced by vertically rotating cylinder Applied Nanoscience $\mathbf{2 0 2 0}$

[6] Khan M I, Nigar M, Hayat T and Alsaedi A 2020 On the numerical simulation of stagnation point flow of nonNewtonian fluid (Carreau fluid) with Cattaneo-Christov heat flux Comput. Methods Programs Biomed. 187105221

[7] Tlili I, Naseer S, Ramzan M, Kadry S and Nam Y 2020 Effects of chemical species and nonlinear thermal radiation with 3D maxwell nanofluid flow with double stratification-an analytical solution Entropy 22453

[8] Khan M, Ahmed A and Ahmed J 2020 Boundary layer flow of Maxwell fluid due to torsional motion of cylinder: modeling and simulation Applied Mathematics and Mechanics 41 $667-80$

[9] Riaz M B and Iftikhar N 2020 A comparative study of heat transfer analysis of MHD Maxwell fluid in view of local and nonlocal differential operators Chaos, Solitons \& Fractals 132109556

[10] Farhangmehr1 V, Moghadasi2 H and Asiaei S 2019 A nanofluid MHD flow with heat and mass transfers over a sheet by nonlinear boundary conditions: heat and mass transfer's enhancement J. Cent. South Univ. (2019) 26 $1205-17$

[11] Hayat T, Saleem N and Ali N 2010 Effect of induced magnetic field on peristaltic transport of Carreau fluid Commun. Nonlinear Sci. Numer. Simul. 15 2407-23

[12] Ellahi R, Hussain F, Abbas S A, Sarafraz M M, Goodarzi M and Shadloo M S 2020 Study of two-phase newtonian nanofluid flow hybrid with hafnium particles under the effects of slip Inventions $\mathbf{5} 6$

[13] Shafee A, Arabkoohsar A, Sheikholeslami M, Jafaryar M, Ayani M, Nguyen-Thoi T and Li Z 2020 Numerical simulation for turbulent flow in a tube with combined swirl flow device considering nanofluid exergy loss Physica. A 542122161

[14] Iftikhar N, Baleanu D, Husnine S M and Shabbir K 2019 Magnetohydrodynamic mixed convection flow of Jeffery fluid with thermophoresis, Soret and Dufour effects and convective condition AIP Adv. 9035251

[15] Raza J 2019 Thermal radiation and slip effects on magnetohydrodynamic (MHD) stagnation point flow of Casson fluid over a convective stretching sheet Propulsion and Power Research 8 138-46

[16] Sheikholeslami M, Arabkoohsar A and Ismail K A 2020 Entropy analysis for a nanofluid within a porous media with magnetic force impact using non-Darcy model Int. Commun. Heat Mass Transfer 112104488

[17] Ellahi R, Hussain F, Abbas S A, Sarafraz M M, Goodarzi M and Shadloo M S 2020 Study of two-phase Newtonian nanofluid flow hybrid with Hafnium particles under the effects of slip Inventions. 56

[18] Hsiao K L 2016 Stagnation electrical MHD nanofuid mixed convection with slip boundary on a stretching sheet Appl. Therm. Eng. 98 850-61

[19] Nayak M K 2017 MHD 3D flow and heat transfer analysis of nanofluid by shrinking surface inspired by thermal radiation and viscous dissipation Int. J. Mech. Sci. 125 185-93

[20] Nayak M K, Mehmood R, Makinde O D, Mahian O and Chamkha A J 2019 Magnetohydrodynamic flow and heat transfer impact on ZnO-SAE50 nanolubricant flow due to an inclined rotating disk J. Central South Univ. 26 1146-60

[21] Nayak M K, Shaw S and Chamkha A J 2019 MHD free convective stretched flow of a radiative nanofluid inspired by variable magnetic field Arab. J. Sci. Eng. 44 1269-82

[22] Ahmad M, Muhammad T, Ahmad I and Aly S 2020 Timedependent 3D flow of viscoelastic nanofluid over an unsteady stretching surface Physica A: Statistical Mechanics and its Applications $\mathbf{5 5 1} 124004$

[23] Li F, Sheikholeslami M, Dara R N, Jafaryar M, Shafee A, Nguyen-Thoi T and Li Z 2020 Numerical study for nanofluid behavior inside a storage finned enclosure involving melting process J. Mol. Liq. 297111939

[24] Nayak M K, Shaw S, Ijaz Khan M, Pandey V S and Nazeer M 2020 Flow and thermal analysis on Darcy-Forchheimer flow of copper-water nanofluid due to a rotating disk: a static and dynamic approach J Mater Res Technol. 9 7387-408

[25] Waqas H, Khan S U, Imran M and Bhatti M M 2019 Thermally developed Falkner-Skanbioconvection flow of a magnetized nanofluid in the presence of a motile gyrotactic microorganism: Buongiorno'snanofluid model Phys. Scr. 94115304

[26] Muhammad T, Waqas H, Khan S A, Ellahi R and Sait S M 2020 Significance of nonlinear thermal radiation in $3 \mathrm{D}$ Eyring-Powell nanofluid flow with Arrhenius activation energy J. Therm. Anal. Calorim. 4 1-6

[27] Li Y, Waqas H, Imran M, Farooq U, Mallawi F and Tlili I 2020 A numerical exploration of modified second-grade nanofluid with motile microorganisms, Thermal Radiation, and Wu's Slip Symmetry. 12393

[28] Nayak M K, Wakif A, Animasaun I L and Saidi Hassani Alaoui M 2020 Numerical differential quadrature examination of steady mixed convection nanofluid flows over an isothermal thin needle conveying metallic and metallic oxide nanomaterials: a comparative investigation Arab. J. Sci. Eng. 45 5331-46

[29] Dogonchi A S, Nayak M K, Karimi N, Chamkha A J and Ganji D D 2020 Numerical simulation of hydrothermal features of $\mathrm{Cu}-\mathrm{H}_{2} \mathrm{O}$ nanofluid natural convection within a porous annulus considering diverse configurations of heater J. Therm. Anal. Cal. 141 2109-25 
[30] Khan N B, Khan M I, Khan W A and Nayak M K 2020 Physical importance of entropy generation in fluid flow (Williamson) with non linear radiative heat flux Indian J. Phy. (https://doi.org/10.1007/s12648-02001728-0)

[31] Abbasi F M, Shanakhat I and Shehzad S A 2019 Analysis of entropy generation in peristaltic nanofluid flow with Ohmic heating and Hall current Phys. Scr. 94025001
[32] Gul M, Abbasi F M, Shehzad S A and Shafee A 2020 Entropy generation for peristaltic motion of Carreau's fluid with mixture of ethylene glycol and boron-nitride nanoparticles Phys. Scr. 95035212

[33] Ramesh G K, Shehzad S A, Rauf A and Chamkha A J 2020 Heat transport analysis of aluminum alloy and magnetite graphene oxide through permeable cylinder with heat source/sink Phys. Scr. 95095203 